David Bartha

Central European University, Budapest, Hungary

ORCID: 0000-0002-4083-1736

e-mail: bartha_david@phd.ceu.edu

\title{
Laws of Nature and the Divine Will in Berkeley's Siris
}

DOI: http://dx.doi.org/10.12775/RF.2019.057

\section{Introduction}

The idea behind this paper is very simple: Berkeley was a theological voluntarist in his last major work, the Siris. ${ }^{1}$ While I am focusing on the Siris now, I will mostly assume that Berkeley consistently maintained this position in all his works. Thus, my argumentation might be read between the lines (and occasionally in the footnotes) as defending the unity of Berkeley's thought with respect to his natural philosophy and theology. As is often remarked, the Siris breaks with the style of Berkeley's earlier works and, for many, also questions his strict commitment to immaterialism. ${ }^{2}$ But, if the reading proposed here is correct, its voluntarist characterization of the divine nature and its related views on the

${ }^{1}$ I restrict my investigation to the theological meaning of voluntarism, emphasizing its implications for natural philosophy. Those who expect to read about ethical voluntarism or the divine command theory will be disappointed.

${ }^{2}$ For instance, Catherine Wilson (1994) argues that Berkeley in the Siris accepts the material reality of the microphysical world. Many commentators proposed, however, that Berkeley endorsed corpuscularianism in an idealist form. Downing (1995) holds that though Berkeley became a realist about unperceived particles in the Siris, restricting his instrumentalism to dynamics, he left his earlier metaphysics mostly intact. While Moked $(1971,1986,1988)$ argued that Berkeley adopts corpuscularianism in the Siris (but probably not earlier) in terms compatible with his immaterialism, Garber (1982) proposed that Berkeley was an "immaterialist corpuscularian" even in the Principles. 
laws of nature and the God-world relation link it very naturally to his earlier considerations. In contrast to recent interpretations of the Siris, I will argue that this continuity applies to his voluntaristically motivated scientific methodology as well, which, despite being more open to the existence of corpuscles not perceived by us, when it comes to the way in which we can discover the laws of nature it is still the essentially inductive method of the early works. ${ }^{3}$ The Siris is particularly interesting from the perspective of theological voluntarism underlying these views, as, due to the alleged discontinuities and its Platonic tendencies in general, it seems to be the worst candidate out of all his works for such an interpretation. In what follows, my principal aim is to show how wrong this appearance is.

I define theological voluntarism as the view that the divine will has conceptual, as opposed to temporal, priority over the intellect. The volitional aspect of God is more basic and relevant to how we should conceptualize his nature and his relationship with creation as well as to our understanding of the world than his intellectual and perceptual capacities. The core thesis of voluntarism is, negatively put, that the will does not necessarily follow the dictates of reason; positively, indeed more ambitiously, the divine will is indifferent, free, unconstrained, and God can will and act arbitrarily. As will be clear through the examination of Berkeley's view, this doctrine of divine psychology has serious ramifications for one's take on the modal status of the laws of nature. Indeed, these views on natural philosophy often reveal one's commitment to voluntarism more conspicuously and perspicuously than the abstract and potentially dangerous theological formulations.

It is important to clarify that voluntarism is not simply the view that 'God can do everything', though, historically speaking, it sprang from considerations about God's omnipotence. Intellectualists, the advocates of the opposite view, holding that God's intellect is his dominant attribute, ordinarily endorse the doctrine of divine omnipotence as well through claiming that God can realize everything he wills-even if he cannot will everything. Moreover, they often maintain that, in a logical (or as the medieval philosophers liked to put it, absolute) sense the divine power is limited only by contradictions-even if, metaphysically speaking, it can never be the case that God actually wills something without

3 Many interpreters, including Moked (1971, 1988), emphasize the hypothetico-deductivism in the Siris. Downing (1995, 281 and 2005a, 264) also suggests that Berkeley relaxes his commitment to empiricism in this work. A related thesis of Downing $(1995,294-5)$ I will take issue with in particular is that in the Siris, just as in the De Motu, Berkeley, through construing the Newtonian dynamics in an instrumentalist way, discards the inductivist approach to the laws of nature we found in the Principles. 
his intellect having determined, justified and, for most early modern intellectualists, necessitated it. On the other hand, moderate voluntarists while denying the latter claim also think that God cannot override logical truths, or actualize logically impossible states of affairs. Berkeley, for instance, openly acknowledges that even God cannot perform logically impossible feats (see Notebooks 129 or the Draft of the Introduction to the Principles, Works 2.125). ${ }^{4}$ In this sense, the voluntarist God cannot do literally everything. Of course, voluntarists will say that since these impossible states of affairs have no positive reality at all, they do not limit God's omnipotence. Voluntarism is not identical with the view that 'Everything (outside him) depends on the will of God' either. Accepting this statement is compatible with his will being determined by his intellect necessarily. Also, a widely accepted intellectualist view can satisfy this requirement according to which while the existence of things depend on God's will, their nature or the content of (some of) the laws governing them is independent of divine decisions - being determined, for instance, by the immutable essences of things, eternal truths or, extrinsically, by other intellectual considerations and principles God's will has to respect such as the essential rationality or simplicity of his ways. On this worldview, once God has decided to create the world, at least some laws can be regarded as (hypothetically and extrinsically) necessary, as his intellectual nature is such that he could not have brought about the world with different ones.

So, in the present context, the crucial questions to answer concerning one's voluntarism are the following: 'Is God's (omnipotent) will (on which everything in nature depends) determined by his intellect?', and 'Does God's intellectual nature or any eternal truth entertained by him determine his act of creation and subsequent activity in nature or the content of the laws of nature?' I want to argue that Berkeley would have answered ' $\mathrm{No}^{\prime}$ ' to both questions, just as he did to the corresponding epistemological one, 'Can we know anything necessary about the laws of nature, for instance, by deducing from our concept of the divine nature?'5 Accordingly, I identify four theses that are required to call Berkeley a full-blown voluntarist: (i) God's indifferent, arbitrary and

${ }^{4}$ When I do not refer to the volume and page number of the Works of George Berkeley edited by Luce and Jessop, I cite Berkeley's works by their abbreviated title and the relevant entry or section number.

5 To be sure, answering "no" to the epistemological question only entails an "epistemological voluntarist" position, which might be accepted by anyone who, ontologically or metaphysically speaking, is not committed to theological voluntarism in the sense I defined it earlier. Controversially, Locke might be a good example of this attitude. On a plausible interpretation, by referring to God's good pleasure and arbitrary decisions, Locke simply wants to admit that our knowledge of the workings of his mind and the laws he established in nature is severely limited. 
free will enjoys conceptual priority over his intellectual functions; (ii) nature is directly guided by, and its laws are grounded in, God's will, meaning not only that the physical things have no causal powers or essences which could ground the laws of nature (that is, natural essentialism is false); but also that (iii) God creates and maintains the physical world in accordance with law-like patterns of the phenomena arbitrarily established by particular divine volitions. As a consequence, (iv) whatever we can know about the metaphysically contingent laws of nature we know through induction from our limited experience. ${ }^{6}$ In what follows, I will show that all of these commitments can be found in the Siris.

\section{Natural Philosophy in the Siris}

One obvious issue to start with is Berkeley's well-known attack on mechanical science. As in his earlier works, he puts forward various sorts of criticism in the Siris. According to the strongest line of attack, which might be called metaphysical criticism, the proponents of mechanical science regularly attribute causal efficacy to mind-independent entities, but, in reality, no physical thing has causal power whatsoever, being merely collections of transparent and passive perceptions or appearances.

Natural phenomena are only natural appearances. They are, therefore, such as we see and perceive them. Their real and objective natures are, therefore, the same-passive without anything active, fluent and changing without anything permanent in them. (Siris 292.)

The principles whereof a thing is compounded, the instrument used in its production, and the end for which it was intended, are all in vulgar use termed causes, though none of them be, strictly speaking, agent or efficient. There is not any proof that an extended corporeal or mechanical cause doth really and properly act, even motion itself being in truth a passion. (Siris 155.)

We are not therefore seriously to suppose, with certain mechanic philosophers, that the minute particles of bodies have real forces or powers, by which they act on each other, to produce the various phenomena in nature. (Siris 235.)

${ }^{6}$ Apart from pointing out the deficiencies of some other definitions, I have no space here to justify these criteria as necessary conditions of voluntarism as such. I at least hope that even if not everyone agrees with me that they are necessary-for instance, because Descartes might be regarded as a voluntarist who denies (iv) - most historians of philosophy will accept that they are not only jointly sufficient, but also individually necessary in Berkeley's case. 
But even when he does not invoke immaterialist principles, Berkeley maintains that the only real causes in nature are the spiritual agents, most notably God, on the grounds that neither experience nor reasoning can reveal any material efficient cause.

The order and course of things, and the experiments we daily make, shew there is a Mind that governs and actuates this mundane system, as the proper real agent and cause; and that the inferior instrumental cause is pure æther, fire, or the substance of light (Sects. 29, 37, 136, 149), which is applied and determined by an Infinite Mind in the macrocosm or universe, with unlimited power, and according to stated rules; as it is in the microcosm with limited power and skill by the human mind. We have no proof, either from experiment or reason, of any other agent or efficient cause than mind or spirit. When, therefore, we speak of corporeal agents or corporeal causes, this is to be understood in a different, subordinate, and improper sense. (Siris 154.)

Though scientists often speak about causes, what they should mean by them is secondary to the real cause. The causes mentioned in the scientific theories are either instruments through which or the aims for which the spiritual causes act. Also, the component parts can be regarded as causes in a derivative and inaccurate sense. But science, staying within its boundaries, has nothing to say about the metaphysical question concerning the real cause of natural events. This vital methodological separation of physics or natural philosophy from metaphysics is just as conspicuous in the Siris as it is in the De Motu.

[...] the efficient and final causes [of natural effects] are not of mechanical consideration. Certainly, if the explaining a phenomenon be to assign its proper efficient and final cause, it should seem the mechanical philosophers never explained anything; [...] (Siris 231.)

With respect to the causal explanation, Berkeley firmly believes that

We cannot make even one single step in accounting for the phenomena without admitting the immediate presence and immediate action of an incorporeal Agent, who connects, moves, and disposes all things according to such rules, and for such purposes, as seem good to Him. (Siris 237.)

The mechanical philosophers' inability to account for the phenomena in a metaphysical sense is partly grounded on the fact that we cannot understand how material bodies could produce any experience in the immaterial soul.

It passeth with many, I know not how, that mechanical principles give a clear solution of the phenomena. The Democritic hypothesis, saith Dr. 
Cudworth, doth much more handsomely and intelligibly solve the phenomena than that of Aristotle and Plato. But, things rightly considered, perhaps it will be found not to solve any phenomenon at all; for all phenomena are, to speak truly, appearances in the soul or mind; and it hath never been explained, nor can it be explained, how external bodies, figures, and motions, should produce an appearance in the mind. Those principles, therefore, do not solve, if by solving is meant assigning the real, either efficient or final, cause of appearances, but only reduce them to general rules. (Siris 251.)

Accordingly, the proper aim of science is not to discover the real causes behind the phenomena but to describe the operation of those causes, primarily God, the only significant efficient cause in nature.

[...] their [i.e. the mechanical philosophers'] province being only to discover the laws of nature, that is, the general rules and methods of motion, and to account for particular phenomena by reducing them under, or shewing their conformity to, such general rules. (Siris 231.)

The mechanical philosopher, as hath been already observed, inquires properly concerning the rules and modes of operation alone, and not concerning the cause; forasmuch as nothing mechanical is or really can be a cause. (Siris 249.)

The scientist, unlike the layman, observes regularities not only in the realm of macroscopic entities, but looks for correspondences also between the microscopic parts and the macroscopic objects they constitute. These observations should lead to generalized rules to which the particular phenomena can be reduced.

Though it be supposed the chief business of a natural philosopher to trace out causes from the effects, yet this is to be understood not of agents, but of principles, that is, of component parts, in one sense, or of laws or rules, in the other. (Siris 247.)

[...] from the outward form of gross masses which occupy the vulgar, a curious inquirer proceeds to examine the inward structure and minute parts, and, from observing the motions in nature, to discover the laws of those motions. By the way, he frames his hypothesis and suits his language to this natural philosophy. And these fit the occasion and answer the end of a maker of experiments or mechanic, who means only to apply the powers of nature, and reduce the phenomena to rules. But if, proceeding still in his analysis and inquiry, he ascends from the sensible into the intellectual world, and beholds things in a new light and a new order, he will then change his system, and perceive that what he took for substances and causes are but fleeting shadows; that the mind contains all, and acts all, and is to all created beings the source of unity and identity, harmony and order, existence and stability. (Siris 295, emphasis added) 
Berkeley emphasizes that God's orderly activity in nature is essential to our understanding of the world because it enables us not only to interpret what has happened but also to predict what will probably happen in the future. This order makes possible the scientific knowledge of the patterns running through nature. But without a firm experiential basis for discovering the rules and forming expectations, we could hardly get on with our daily lives either.

There is a certain analogy, constancy, and uniformity in the phenomena or appearances of nature, which are a foundation for general rules: and these are a grammar for the understanding of nature, or that series of effects in the visible world whereby we are enabled to foresee what will come to pass in the natural course of things. (Siris 252.)

Mechanical laws of nature or motion direct us how to act, and teach us what to expect. Where intellect presides there will be method and order, and therefore rules, which if not stated and constant would cease to be rules. There is therefore a constancy in things, which is styled the Course of Nature (Sect. 160). (Siris 234, for section 160 see later)

As Berkeley consistently believed from his first publication to his last, the whole of nature is a divine language, a set of semantic relations between signs and signified things organized in a syntactic order. Our understanding of this rational, "coherent, entertaining, and instructive Discourse" with God depends on how much relevant experience we have and how skillfully and attentively we interpret that experience.

[...] the phenomena of nature are alike visible to all; but all have not alike learned the connexion of natural things, or understand what they signify, or know how to vaticinate by them. [...] As the natural connexion of signs with the things signified is regular and constant, it forms a sort of rational discourse (Sect. 152), and is therefore the immediate effect of an intelligent cause. This is agreeable to the philosophy of Plato, and other ancients. $[\ldots]$ Therefore, the phenomena of nature, which strike on the senses and are understood by the mind, form not only a magnificent spectacle, but also a most coherent, entertaining, and instructive Discourse; and to effect this, they are conducted, adjusted, and ranged by the greatest wisdom. This Language or Discourse is studied with different attention, and interpreted with different degrees of skill. But so far as men have studied and remarked its rules, and can interpret right, so far they may be said to be knowing in nature. A beast is like a man who hears a strange tongue but understands nothing. (Siris 253-254.)

Unlike in the New Theory of Vision or the Alciphron, but like in the Principles, Berkeley does not restrict the analogy of divine language to the visual data in the Siris. For our purposes now, the most important 
implication of the analogy between language and the physical world is that there is nothing necessary in nature. Just as any natural language is based on conventional semantic relations and syntactic rules, so too the relations and correspondences in nature are arbitrarily determined by, and contingent on, the divine will. Furthermore, the successful communication in both the human and divine languages depends partly on the recipient's previous knowledge, skills and attention in interpreting the raw information received.

\section{The Voluntarist Understanding of Nature}

The doctrine of the divine language anticipates Berkeley's view that the patterns of our perceptions, equivalent to the syntactic structure of language, do not constitute any necessary laws of nature. On the proposed interpretation, what Berkeley argues for is not simply the view that it is, or rather was, in God's absolute power as a purely logical possibility to choose other laws, nor is it simply the view that God could have freely decided not to create the world and hence implement any law at all. Rather, on the voluntarist reading, the strong metaphysical contingency of the laws means for Berkeley that, since there is nothing about the essences of things or of the intellectual nature of the divinity that could, at least, extrinsically determine the laws, God could really have decided to act according to other, if any, regularities. Indeed, in the Notebooks (734-5) and the Principles (107) Berkeley openly embraces the natural but, for some, radical implication of voluntarism to the effect that God still could at any time change the actual rules of his activity in nature. This understanding of the laws excludes not only their absolute and logical but also their hypothetical and metaphysical or extrinsic necessity. This, alongside with all the voluntarist commitments I have delineated above, is made clear in the Siris.

To start with the epistemological side of the story (iv), in his early works Berkeley emphasized that laws of nature are known by us as a result of observation and inductive generalizations (see, for instance, Principles 30, 58, 62 and 104). In the Siris, too, he claims that the discovery of the general rules or methods applied by God in nature must be based on particular experiences of the divine action. In passages such as Siris 252, 254 and 295 (quoted above), he claims that observing the motions in nature and paying attention to the rules of the divine discourse or the uniformity of our perceptions serve as the foundation for our understanding of the laws of nature. Though reasoning leads us to God, the real metaphysical cause, it is sense experience that reveals the rules behind the ordinary course of nature. 
Sense and experience acquaint us with the course and analogy of appearances or natural effects. Thought, reason, intellect introduce us into the knowledge of their causes (Siris 264.)

Similarly, in the diversely interpreted section 228 , he suggests that the laws of nature cannot be discovered without apt observation or by framing a priori hypotheses.

It is one thing to arrive at general laws of nature from a contemplation of the phenomena, and another to frame an hypothesis, and from thence deduce the phenomena. Those who supposed epicycles, and by them explained the motions and appearances of the planets, may not therefore be thought to have discovered principles true in fact and nature. And, albeit we may from the premises infer a conclusion, it will not follow that we can argue reciprocally, and from the conclusion infer the premises. (Siris 228.)

Moked (1971, 259-265), Downing (1995, 293-294) and Hight (2010, 26) interpret this passage differently. According to them, Berkeley offers here two possible and legitimate methods of doing science: an inductive and a hypothetical-deductive model. ${ }^{7}$ In contrast, on my less original reading, Berkeley plainly rejects the latter and follows Newton's famous inductive principle. ${ }^{8}$ In order to see this, we need to differentiate the method of inferring the existence of certain unperceived entities (like corpuscles) based on our actual experience from the hypothetico-deductive model as Berkeley and Newton understood it, according to which we could discover the rules God established in nature by first framing some a priori hypotheses (for instance, as the Cartesians sought to do it, based on our concepts of divine nature or extension) then check if they can be used to deduce, i.e. calculate and predict our experience accurately. While they both rejected the latter as a scientific method of discovering the actual laws of nature, the former in an instrumentalist, or even realist, manner was problematic neither for Berkeley nor for Newton.

7 With primarily the De Motu in mind, Buchdahl writes in a similar vein that we should not simply conclude that "[...] Berkeley must be an 'inductivist Newtonian', who is vocal in his opposition to 'hypotheses' [...]." In fact, he claims that his idealism "drives Berkeley to a more sustained employment of a hypothetico-deductive approach." (Buchdahl 1969, 291, n1.)

8 See, among others, the General Scholium of Book III of the Principia, which, along with various methodological remarks from the Opticks, clearly made a great impression on Berkeley: "I have not as yet been able to deduce from phenomena the reason for these properties of gravity, and I do not feign hypotheses. For whatever is not deduced from the phenomena must be called a hypothesis; and hypotheses, whether metaphysical or physical, or based on occult qualities, or mechanical, have no place in experimental philosophy. In this experimental philosophy, propositions are deduced from the phenomena and are made general by induction." (Newton 1999, 943.) 
I see no reason to think that the inductive understanding of nature Berkeley and Newton subscribed to necessarily excludes the supposition of unobserved microscopic entities. They might justify theorizations like this-deductions from phenomena, as Newton called it - in two ways: the experienced generalities might suggest the existence of some unobserved entities as an inference to the best explanation of the phenomena ${ }^{9}$ or provide an analogical basis for anticipating or predicting that the observed structural regularities continue uniformly in the unobserved world, even if we might never be in a position to confirm this assumption. ${ }^{10}$ To be sure, an inductive generalization might not only include or extend to suppositions of directly not perceived but probabilistically inferred (if you like, a posteriori hypothesized) entities, but the inductive generalization itself might also be considered a hypothetical theory, insofar as new experiential data could restrict its scope or modify and specify how it should be formulated. ${ }^{11}$ But while what Newton called a theory or proposition is ultimately based on experience, even if what it presupposes is not directly perceived but only inferred from, or suggested by, our actual observations, the hypotheses both he and Berkeley denounced are not made on the basis of any earlier experience, but being put forward straightaway as universal, "all-or-nothing" claims tested against our particular observations and experiments only afterwards. ${ }^{12}$

In her careful examination, Lisa Downing $(1995,294-5$.) points to two features of Newtonian dynamics which, she claims, led Berkeley to conclude that it falls into the hypothetico-deductive category. ${ }^{13}$ First, it in-

9 The entailment that we are justified to suppose nothing more than what is required by our experience is endorsed by Berkeley, for instance, when claiming that "It doth not seem necessary, from the phenomena, to suppose any medium more active and subtle than light or fire" (Siris 225).

10 The uniformity of great and small is endorsed in Siris 234 and 283 for instance. Cf. Downing 1995, 295-6.

11 Since even the most cautious induction is based on a limited amount of experience and always open to refinement, it yields only probable and fallible results or hypotheses (cf. Siris 295, quoted above), which is in line with Berkeley's early acknowledgment that "our knowledge of the Laws of nature is not perfect" (Notebooks 221). But, as Newton's fourth rule of natural philosophy points out, unlike in the case of the hypothetico-deductive model, in which an incompatible result would simply falsify the proposed hypothesis, an inconsistent observation in itself does not falsify, or even raise serious doubts about, the inductive generalization, as the resulting qualifications added to the formulation just make it more precise (see Newton 1999, 796). Accordingly, as I will suggest later, for Berkeley, the laws of nature need not to be exceptionless regularities.

${ }^{12}$ Cf. Brook's analysis $(1973,96-98)$ of Siris 228, according to which Berkeley follows Newton in rejecting what Brook calls ad hoc hypotheses, such as the Cartesian vortex-theory.

13 While Downing related Berkeley's instrumentalism about the Newtonian dynamical concepts to the hypothetico-deductive model, and his realism about particles 
vokes forces, which do not, and cannot, have an experiential basis and hence cannot serve as the basis for an induction, but can be posited merely as a useful hypothesis. Secondly, in the De Motu, Berkeley regards a generalization as a genuine law of nature only if it enables us to deduce other regularities in nature. Indeed, a Newtonian law of motion might not correspond directly to any inductive generalization (see Downing 2005a, 250). ${ }^{14}$ However, as we have seen, classifying the Newtonian approach into the hypothetico-deductive category would be a direct assault against Newton's own assessment. Moreover, while, as we will see later, in other passages Berkeley makes clear his endorsement of, indeed admiration for, the Newtonian science, in this passage he seems to be critical of the hypothetico-deductive model-after all, what it produces are mere hypotheses, not the actual laws of nature. Hence, it seems to me highly unlikely that in Siris 228 Berkeley wanted to say that Newton employed the same methodology as Ptolemy and, indeed, did not "discover principles true in fact and nature" (my emphasis). ${ }^{15}$ Even though this quote taken in isolation might refer to the essentialist or realist understanding of the Newtonian dynamical concepts, he criticizes in the Siris just as clearly as in De Motu, the context makes clear it is not the case. ${ }^{16}$

to inductivism, for Moked, in sharp contrast, Berkeley's commitment to the hypothetico-deducitve model is established by his assumption of unperceived particles, and the traditional inductivist picture is retained for the Newtonian approach of (primarily) the earlier works. In the earlier paragraph, I was taking issue with Moked's association of the supposition of corpuscles with the hypothetico-deductive model. In this paragraph, I will raise doubts about Downing's claim that Berkeley's understanding of the Newtonian dynamical concepts entails that he endorsed the hypothetico-deductive model.

14 Stoneham - Cei $(2009,77)$ also claims that Berkeley in the De Motu "is more open to there being projectible, highly general laws which are not based on induction", and, since "we may not have observed attraction (as opposed to its alleged effects)", "laws of attraction are not discovered by inductive generalization on experienced correlations".

${ }^{15}$ Cf. Siris 245 , to be quoted partly in footnote 28 , where Berkeley asserts that Newton "opened several deep secrets of nature".

${ }^{16}$ It is worth noting that, in Berkeley's view, Newton never thought that the laws of motion correspond to some forces inherent in the bodies (see, for instance, De Motu 17). For him, the Newtonian inductive science is absolutely compatible with the denial of physical forces. As he writes to Johnson, "The true use and end of natural philosophy is to explain the phenomena of nature, which is done by discovering the laws of nature, and reducing particular appearances to them. This is Sir Isaac Newton's method; and such method or design is not in the least inconsistent with the principles I lay down." (Works 2.279.) So, Berkeley could not have meant it as a criticism of Newton himself. To be fair, neither Downing nor Moked reads this passage to be critical of the hypothetico-deductivist approach. 
In the quoted passage (and its continuation) ${ }^{17}$, the contrast Berkeley seeks to underline is between different methodologies and their capabilities of revealing the actual principles or structure of reality rather than between the metaphysical status of entities or properties which the inductive generalizations describes and entities or properties which the hypotheses posit to deduce the phenomena.

Moreover, it is unclear to me why speaking about forces in an antirealist or instrumentalist way would mean that Berkeley breaches the limits of inductivism and surrenders to the hypothetico-deductive model? On my understanding, they are not necessarily competing theories. What Berkeley aims to do with the dynamic terminology is not to hypothesize in an instrumentalist manner about hidden forces or causes in order to deduce the (otherwise unexplained) effects we experience but rather to provide us with a mathematical tool for abbreviating and simplifying complex inductive generalizations about various motions with the aim of making them easier to use for prediction and calculation. ${ }^{18}$ But even if he thought that the dynamic concepts, unlike the supposition of corpuscles, can have no inductive but only instrumentalist justification, with respect to the subject matter of the passage-the laws of nature-it is clear that Berkeley does not want to deny that there are "principles true in fact and nature" (Siris 228.). As we will see, the laws of attraction are indeed regarded as true laws of motion, insofar as they are proper generalizations based on, and in line with, the most convincing experiential and experimental data, revealing the nomological order God has decreed..$^{19}$ Also, the example of epicycles is interesting -in ad-

17 " [...] For instance, supposing an elastic fluid, whose constituent minute particles are equidistant from each other, and of equal densities and diameters, and recede one from another with a centrifugal force which is inversely as the distance of the centres; and admitting that from such supposition it must follow that the density and elastic force of such fluid are in the inverse proportion of the space it occupies when compressed by any force; yet we cannot reciprocally infer that a fluid endued with this property must therefore consist of such supposed equal particles; for it would then follow that the constituent particles of air were of equal densities and diameters; whereas it is certain that air is a heterogeneous mass, containing in its composition an infinite variety of exhalations, from the different bodies which make up this terraqueous globe." (Siris 228.)

${ }_{18}$ It does not mean that we can directly reduce all the force-talk to generalities of observed motions because, as I suggested earlier, there might be inductive generalizations which include or extend to actually unobserved, and even (practically) unobservable, entities and motions.

19 As far as I can see, Berkeley's approach to the laws of nature is rarely distinguished from his attitude towards their theoretical posits, such as forces. Downing, for instance, takes Berkeley's view to be that the Newtonian laws of motion are justified in the same instrumentalist way as the dynamical concepts are, as "their importance lies in their applicability, not in descriptive content (which Berkeley ultimately thinks 
dition to my earlier suggestion that it would be deeply inappropriate, if not ironic, to associate it with Newton. For Berkeley, the hypothesis of epicycles is nothing like the Newtonian theory of universal attraction. To be sure, Berkeley criticizes the theory of epicycles not because it attributes anything (such as some inherent force, e.g. centripetal force) to the planets they do not actually have (as opposed to speaking in instrumentalist terms), but because it is based on a hopeless methodology which starts from a hypothesis that has no experiential grounding at all, trying merely to provide a theoretical framework to calculate and predict the observed movements of the planets. But, as Berkeley emphasizes, this method does not work the other way around (as he puts it, "it will not follow that we can argue reciprocally, and from the conclusion infer the premises"), that is, the experience the hypotheses might help us predict and calculate cannot ground the truth of the theory as a genuine law of motion. Unlike the dynamical concepts, the justification of a theory about the actual rules of nature cannot come merely from its utility or predictive power. Though the hypothesis of epicycles might be as useful in predictions or calculations as the Newtonian theories about planetary motions, it is wrong since its methodology is invalid and inadequate to reveal the real rules according to which God tends to bring about the phenomena. ${ }^{20}$

The fact that deduction or a priori reasoning has a role in Berkeley's philosophy of science should not bother us either. He never denied this:

The natural or mechanic philosopher endeavours to discover those laws [the laws of motion] by experiment and reasoning. (Siris 234.)

By induction we come up with initial generalizations of the phenomena, but, as he realized from the De Motu onwards, we can regard only those generalizations as real laws of nature from which other less broad generalizations can be deduced. Of course, not only building this hierarchical structure of increasing levels of generality, but every single inductive generalization needs more than just mere observation, since we need to render them universal by pure reasoning and, possibly, formalization (see De Motu 36.). ${ }^{21}$ Nonetheless, even the most general laws

they lack)" (Downing 2005a, 251). Recently, Ott (2019) challenged the instrumentalist reading of Berkeley. See also Hight 2010 and Peterschmitt 2009.

20 Accordingly, in the Analyst 10, Berkeley warns us not to "confound the usefulness of a rule with the certainty of a truth". See various assertions in the Alciphron, for instance 2.24, 3.16, 4.1. For an insightful analysis of how truth and usefulness, though related, come apart for Berkeley, see Pearce 2017, 158-162. See footnote 30.

${ }^{21}$ As Brook $(1973,91-92)$ maintains, the general rule or law of nature (referred to, for instance, in the Principles 104) that is supposed to explain its particular instances 
as well as the way we organize the various regularities according to their levels of generality ultimately need to go back to the empirical data captured by the initial inductive generalizations. I see no reason to think with Downing and others that Berkeley meant anything more than this when he acknowledged that mathematization, universal formulation, and even deduction are part of the essentially inductive method of discovering the laws of nature.

As for (ii), Berkeley leaves no room for doubting that God's omnipotence entails that he and his actions in the natural world are not bound by the essences of physical things. To put it in the idealist terms of Berkeley's earlier works, God is not bound by necessary relations between properties of perceptions constituting the physical world (for instance, that the visual experience of fire has to be accompanied by a hot feeling). He makes it clear not only through the analogy of divine language, but also explicitly by claiming that the "Infinite Mind in the macrocosm or universe, with unlimited power" (Siris 154.) "connects, moves, and disposes all things according to such rules, and for such purposes, as seem good to Him" (Siris 237). To quote the whole passage:

So likewise, how to explain all those various motions and effects by the density and elasticity of æther seems incomprehensible (Sects. 153, 162). For instance, why should the acid particles draw those of water and repel each other? Why should some salts attract vapours in the air, and others not? Why should the particles of common salt repel each other, so as not to subside in water? Why should the most repellent particles be the most attractive upon contact? Or why should the repellent begin where the attractive faculty leaves off? These, and numberless other effects, seem inexplicable on mechanical principles, or otherwise than by recourse to a mind or spiritual agent (Sects. 154, 220). Nor will it suffice from present phenomena and effects, through a chain of natural causes and subordinate blind agents, to trace a divine Intellect as the remote original cause, that first created the world, and then set it a-going. We cannot make even one single step in accounting for the phenomena without admitting the immediate presence and immediate action of an incorporeal Agent, who connects, moves, and disposes all things according to such rules, and for such purposes, as seem good to Him. (Siris 237, emphasis added)

As (ii) demands, the divine actions are clearly not restricted by the essences or powers of bodies, as God acts according to any rule or purpose that "seem[s] good to Him". This passage also suggests that we have no direct knowledge of these purposes, if any, behind the divine decisions, and we can only figure them out from the effects retrospectively (reinforcing thesis (iv) again). With the quoted qualification, however,

should not be a simple inductive generalization but rather a mathematical law. 
Berkeley might have wanted to add a stronger voluntarist twist to the statement, hinting at the crucial commitment (iii), as well. Obviously, this clause might be endorsed by an intellectualist as well in the sense that God needs to regard whatever he is going to create as good, but, on my reading, in this particular context it more aptly expresses the voluntarist thought that, beyond the fact that God decided so, no reason, rule or purpose of the divine action is to be looked for to account for any natural event. God wills things just because he does, and his actions and decisions require no underlying reason or principles to ground and justify them. In contrast to supposing some autonomous and self-sufficient laws a divine intellect simply got up and running, the only proper way to account for the phenomena is accepting and starting from the arbitrary nature of the divine agent's immediate actions in nature. So, this passage concerns not only, as I noted earlier, the causal or metaphysical explanation of nature, but also the modal status of the laws of nature and the proper way of doing science. In other words, it claims not only that God is the real cause of natural events, but also that this cause is to be construed as a free agent acting according to rules arbitrarily established by him, as opposed to a divine intellect which in creating the world merely puts some principles and/or natural causes into operation and motion.

Why may we not suppose certain idiosyncrasies, sympathies, oppositions, in the solids, or fluids, or animal spirit of a human body, with regard to the fine insensible parts of minerals or vegetables, impregnated by rays of light of different properties, not depending on the different size, figure, number, solidity, or weight of those particles, nor on the general laws of motion, nor on the density or elasticity of a medium, but merely and altogether on the good pleasure of the Creator, in the original formation of things? From whence divers unaccountable and unforeseen motions may arise in the animal economy; from whence also various peculiar and specific virtues may be conceived to arise, residing in certain medicines, and not to be explained by mechanical principles. For although the general known laws of motion are to be deemed mechanical, yet peculiar motions of the insensible parts, and peculiar properties depending thereon, are occult and specific. (Siris 239, emphasis added)

This passage straightforwardly-and in terms that cannot be dismissed as merely epistemological-denies both natural essentialism ("not depending on the different size, figure, number, solidity, or weight of those particles") and a more Malebranchean intellectualist alternative according to which general laws, for instance of motion, either fully determine or significantly constrain the various processes and interactions God could actualize in nature. So, as (iii) requires from a voluntarist, Berkeley argues that the way God acts in nature is not only, as (ii) claims, independent of the natures or causal powers posited by the materialists 
in the physical objects, but even of any universal rule, like a general law of motion, that could necessarily determine how God has to act in all instances and circumstances in the non-miraculous course of nature. Everything in nature depends on God's will in a strong sense: not only in the sense that he actualizes and executes the laws of nature through his volitions, but also that it is absolutely up to his "good pleasure" what and how he creates. ${ }^{22}$ Berkeley emphasizes that overstretched generalizations and claims about universality need to be handled with caution, if not suspicion, since the peculiar, specific and even "occult" ways God implements in nature are hardly accountable by simple mechanical laws or indeed by any general principle.

Some corpuscularian philosophers of the last age have indeed attempted to explain the formation of this world and its phenomena by a few simple laws of mechanism. But if we consider the various productions of nature, in the mineral, vegetable, and animal parts of the creation, I believe we shall see cause to affirm that not any one of them has hitherto been, or can be, accounted for on principles merely mechanical; and that nothing could be more vain and imaginary than to suppose with Descartes that merely from a circular motion's being impressed by the supreme Agent on the particles of extended substance, the whole world, with all its several parts, appurtenances, and phenomena, might be produced by a necessary consequence from the laws of motion. (Siris 232.)

The Cartesian laws of motion, especially the infamous vortex-theory, fail to do justice to the variety and diversity of the natural phenomena. As Berkeley makes it clear, it is not a personal failure, but the very idea of reducing the various motions in nature to a few simple mechanical laws that necessarily and universally determine them is fundamentally

22 The expression "good pleasure" of God is pretty telling in itself. While Locke regularly attributes the otherwise unaccountable phenomena to God's good pleasure (see, for instance, Essay IV.iii.6, IV.iii.29), intellectualists such as Leibniz made it clear that, if there is such a thing at all, the divine good pleasure is always ruled by God's wisdom (see Leibniz 1989, 352.). In any event, Berkeley understood the expression in the same way as Mary Astell did when she asked Norris if God "may according to the good pleasure of His Omnipotency, give [a triangle] a good speaking, a walking, or a dancing faculty, and make it able to Eat and Drink [...]" (Astell 1705, 254-255). For Berkeley, God's good pleasure is not restricted to the scientific or philosophical difficulties we cannot account for but applies to the whole universe, its nature just like its existence. With regard to such a basic scientific concept as gravity (which is even more essential for an attractionist like Berkeley), he says in Principles 106: "[...] there is nothing necessary or essential in the case [of gravity], but it depends entirely on the will of the governing spirit, who causes certain bodies to cleave together, or tend towards each other, according to various laws, whilst he keeps others at a fixed distance; and to some he gives a quite contrary tendency to fly asunder, just as he sees convenient." 
misguided. The world is not "going like a clock or machine by itself, according to the laws of nature, without the immediate hand of the artist" (Siris 233). In order to make sense of the variety of the phenomena, God's free and arbitrary activity is needed to be acknowledged in every particular type of motion. Note that it is not merely to advocate occasionalism - the view that it is God himself, and not the physical objects, that acts in nature through the general laws of motion-or to claim that God can bring about miracles any time he wants. More importantly, the position Berkeley holds is that the particular ways of God's ordinary activity, however regular they are one by one, cannot be reduced to a couple of general principles.

All the phenomena in nature are produced by motion. There appears a uniform working in things great and small, by attracting and repelling forces. But the particular laws of attraction and repulsion are various. (Siris 234.)

While our experience of the particular phenomena is clear, sticking to general laws to explain them might lead in some cases to far-fetched and obscure or, as he puts it in Siris 237, "incomprehensible" theories and conclusions. ${ }^{23}$ We just have to accept that we cannot explain everything in nature by a few universal principles, let them be Cartesian or Newtonian laws.

The minute corpuscles are impelled and directed, that is to say, moved to and from each other, according to various rules or laws of motion. The laws of gravity, magnetism, and electricity are diverse. And it is not known what other different rules or laws of motion might be established by the Author of nature. Some bodies approach together, others fly asunder, and perhaps some others do neither. When salt of tartar flows per deliquium, it is visible that the particles of water floating in the air are moved towards the particles of salt, and joined with them. And when we behold vulgar salt not to flow per deliquium, may we not conclude that the same law of nature and motion doth not obtain between its particles and those of the floating vapours? A drop of water assumes a round figure, because its parts are moved towards each other. But the particles of oil and vinegar have no such disposition to unite. And when flies walk in water without wetting their feet, it is attributed to a repelling force or faculty in the fly's feet. But this is obscure, though the phenomenon be plain. (Siris 235, emphasis added)

${ }^{23}$ The danger of overgeneralization is also mentioned in Principles 106, partially quoted in the previous footnote. I have to add, however, that by the time of the Siris, Berkeley realized that due to his conception of God and nature we should have even less confidence in any universal law. 
As Berkeley makes clear in Siris 261, "in the mundane system, the steady observance of certain laws of nature, in the grosser masses and more conspicuous motions, doth not hinder but a voluntary agent may sometimes communicate particular impressions to the fine æthereal medium". ${ }^{24}$ Indeed, God might act in ways radically different from those we imagine right now. It just reinforces what we have already seen in Siris 237, namely that lots of "effects, seem inexplicable on mechanical principles", and we might not be able to figure out "what other different rules or laws of motion might be established by the Author of nature" (Siris 235), since "divers unaccountable and unforeseen motions may arise" (Siris 239) at any time or place, especially with regard to the imperceptible microworld. While some of these passages are open to various interpretations, emphasizing, as he did most clearly in Siris 239, God's pleasure and freedom in deciding about the laws of nature, the particularity and arbitrariness of his actions, Berkeley goes further than merely maintaining a Lockean sort of epistemological voluntarist view. On this stronger, metaphysically construed, voluntarist worldview, God does not necessarily follow any intellectual principles, which could ground the most basic laws of motion. As Siris 232 and 237 suggested, were God to act simply by executing some necessary laws, he might just leave them to do the work on their own. If God's role is only to bring the world about with laws that are necessary and universal, it seems to leave, apart from his keeping the world and its laws in existence, all of God's direct involvement, his particular decisions and activities redundant. In this sense, intellectualism and the uncritical adherence to the general mechanical laws of nature might easily lead to deism, and hence was a deeply problematic set of theological, metaphysical and natural philosophical views for Berkeley.

Nonetheless, as we have seen earlier, Berkeley, just as much as Malebranche, was convinced that the world is generally ordered. To be sure, Berkeley as a voluntarist needs merely to deny that God does, or rather has to, act through highly general principles universally. The particularity of the divine actions and decisions in nature does not entail extreme arbitrariness or capriciousness on God's part, potentially leaving us with no discoverable patterns in the natural world to do engineering, science, etc. ${ }^{25}$ Indeed, Berkeley thinks that the world of perceptions with-

${ }^{24}$ Interestingly, in quite a modern way, Berkeley makes a distinction between the macro- and the microphysical. Despite a general uniformity or analogy between "things great and small" (Siris 234.), while the former seems to obey the observed regularities more faithfully, the latter is much more unpredictable and chaotic. Nonetheless, as Principles 106 and Siris 235 suggest, gravity is not universally true of the medium-sized dry goods either.

${ }^{25}$ So, despite the commonly raised criticism, voluntarists never thought that God acts randomly and capriciously. Actually, God might even have general reasons for 
out some observable generalities and correspondences would be utterly incomprehensible and pointless from the finite perceiver's essentially practical point of view. As he put in Siris 234, quoted above, "if not stated and constant [the rules of nature] would cease to be rules". Nonetheless, unlike Malebranche or other intellectualists, Berkeley thought that a chaotic world is not incompatible with God's nature, and God himself is not necessitated by his intellect to create and/or maintain a simple and ordered universe, let alone the most simple and ordered one. As he emphasized, the generally regular course of nature is a necessity only for us, but not for God, who acts in the orderly way he determined absolutely freely. In other words, the order of nature is not a requirement of his intellectual nature but comes from his free decisions to communicate with us in a way we can comprehend. ${ }^{26}$ This is clearly consistent with his commitments both to the divine freedom, arbitrariness and particularity of God's actions on the one hand, and the observable extent of the generality of the laws of nature on the other.

The mind of man acts by an instrument necessarily. The to hegemonikon or Mind presiding in the world, acts by an instrument freely. Without instrumental and second causes there could be no regular course of nature. And without a regular course, nature could never be understood; mankind must always be at a loss, not knowing what to expect, or how to govern themselves, or direct their actions for the obtaining of any end. Therefore in the government of the world physical agents, improperly so called, or mechanical, or second causes, or natural causes, or instruments, are necessary to assist, not the Governor, but the governed. (Siris 160, emphasis added)

his actions. The point is simply that He is not determined by these, and hence we cannot even hope to find principles irresistible for God, which, as a consequence, are necessarily and universally implemented in nature. So, a voluntarist might say, as Berkeley did, that God acts according to (at least to some extent) general laws with a purpose in his mind, namely our benefit, but he does not have to act according to strictly universal laws and could freely, and, at any time, do otherwise, since there are neither intellectual standards to measure and evaluate his actions nor requirements to determine and limit his decisions.

${ }^{26}$ Though in this article I am focusing on the metaphysical contingency of the laws - the view not simply that God could suspend the actual laws, but also that we could have altogether different laws governing nature-these considerations suggests that Berkeley thinks that the laws are not even physically or nomologically necessary. The laws of nature are tendencies, rather than exceptionless regularities, of God's actions, which have to be (in the sense of practical necessity) regular to the extent we can realize them, but there is nothing universal, essential, or necessary about them even in the non-miraculous course of nature. 
Berkeley's voluntarism might also explain why he prefers Newtonian attractionism to the Cartesian impact-based strict mechanism. ${ }^{27}$ In Siris 231, he maintains that the observed rules of attraction are genuine laws of motion.

The laws of attraction and repulsion are to be regarded as laws of motion; and these only as rules or methods observed in the productions of natural effects [...] (Siris 231.)

Berkeley even explicitly contrasts Newton's explanation with that of Descartes, implying not only that the rules of attraction are just as basic as, and cannot be reduced to, the strictly mechanical laws, but actually claiming that, in general, attractionism, being in accordance with our experience that there is a "uniform working in things great and small, by attracting and repelling forces" (Siris 234), provides a better description of nature than an impact-based mechanism..$^{28}$

Nature seems better known and explained by attractions and repulsions than by those other mechanical principles of size, figure, and the like; that is, by Sir Isaac Newton, than Descartes. And natural philosophers excel, as they are more or less acquainted with the laws and methods observed by the Author of nature. (Siris 243, emphasis)

The pure æther or invisible fire contains parts of different kinds, that are impressed with different forces, or subjected to different laws of motion, attraction, repulsion, and expansion, and endued with divers distinct habitudes towards other bodies. [...] The different modes of cohesion, attraction, repulsion, and motion appear to be the source from whence the

${ }^{27}$ In the previous discussion, and in the quotes from Berkeley, the term "mechanical" and its variants referred primarily to early modern science in general, and it is often used to underline the contrast with Berkeley's view that only spiritual agents can be real causes. The category of mechanical philosophers includes Newtonian "not strict" mechanists as well, who agree with the Cartesian "strict" mechanists that the natural phenomena can be accounted for in terms of general laws describing the motions of various bodies. Strict mechanists add that these explanations are to be restricted, or reduced, to laws of impact. Cf. the helpful definitions of these terms given by Downing (2005b).

${ }^{28}$ In the Principles (110), as well, Berkeley asserted that, despite its mistakes about absolute time, space and motion, Newtonian physics and, in particular, "a certain celebrated treatise of mechanics" provide "the best key for [...] natural science". In the Siris (245), Berkeley specifies Newton's achievement, claiming that "by his singular penetration, profound knowledge in geometry and mechanics, and great exactness in experiments, hath cast a new light on natural science. The laws of attraction and repulsion were in many instances discovered, and first discovered, by him. He shewed their general extent, and therewith, as with a key, opened several deep secrets of nature, in the knowledge whereof he seems to have made a greater progress than all the sects of corpuscularians together had done before him". 
specific properties are derived, rather than different shapes or figures. (Siris 162.)

A natural way to read these passages is that strict mechanism is less capable of accounting for our diverse experience about the motions God decided to bring about in nature, and as such does not provide us with the best understanding of the laws of nature available to us. Though the text does not explicitly confirm this, it might also fall short of the broader applicability and greater predictive power of attractionism. But, as Berkeley made clear in the Siris, even the experimentally more justified theory of attractionism is only our best shot, our best approximation of capturing the diverse rules of divine activity, and tells us nothing objectively or independently true that could underlie and explain God's specific actions and decisions. With regard to the various and specific laws of attraction and repulsion, he claims that even the attractive or repelling forces are "to be regarded only as a mathematical hypothesis" ${ }^{29}$

Nor are we concerned at all about the forces, neither can we know or measure them otherwise than by their effects, that is to say, the motions; which motions only, and not the forces, are indeed in the bodies (Sect. 155). Bodies are moved to or from each other, and this is performed according to different laws. [...] But what is said of forces residing in bodies, whether attracting or repelling, is to be regarded only as a mathematical hypothesis, and not as anything really existing in nature. (Siris 234.)

The forces supposed by the Newtonian attractionist theory do not actually exist in the physical entities, and "the principle of attraction itself is not to be explained by physical or corporeal causes" (Siris 245.)

[...] although it shews not the agent, yet it sheweth a rule and analogy in nature to say that the solid parts of animals are endued with attractive powers whereby from contiguous fluids they draw like to like; and that glands have peculiar powers attractive of peculiar juices [...] (Siris 234.)

But these forces are real, nonetheless, as long as construed as the immediate action of God, who is the incorporeal principle or agent of attraction. Speaking about attractive and repulsive forces in bodies means in simplified and mathematized terms that God established laws according to which they move as if they attracted and repulsed one another. ${ }^{30}$

${ }^{29}$ As is well-known, Berkeley argues against the essentialist or realist reading of Newtonian dynamics in the De Motu as well, that is, against the view that forces are inherent and real in bodies.

${ }^{30}$ As I mentioned earlier, even if Berkeley was an instrumentalist about the dynamical concepts, taking them merely for useful signs, he is a realist in the sense that though the discovered laws of nature are without further physical grounding, 
[...] the great men of antiquity resolved gravity into the immediate action of an intelligent incorporeal being. To which also Sir Isaac Newton himself attests and subscribes; although he may perhaps sometimes be thought to forget himself in his manner of speaking of physical agents, which in a strict sense are none at all, and in supposing real forces to exist in bodies, in which, to speak truly, attraction and repulsion should be considered only as tendencies or motions, that is, as mere effects, and their laws as laws of motion. (Siris 246.)

In fact, strict mechanism and attractionism might not disagree substantially on the experiential data they aim to capture, as both theories acknowledge, as the explanandum, that certain objects located at a distance move towards each other. Moreover, their predictive value is often very similar and can yield similarly appropriate calculations. So, my contention is that Berkeley preferred the Newtonian approach to the Cartesian one not merely because it has more predictive success, but because it allows for a voluntarist understanding of God. The Newtonian inductive approach is more in line with Berkeley's conception of nature and God, according to which it is just as pointless to seek to understand God's nature or any eternal truths in order to deduce the laws of nature as to try to discover the hidden essence or natures of bodies. The real aim of science is rather to describe and cautiously generalize from the observed regularities, correspondence and analogies discovered by experiment (and subsequent reasoning) in nature. On these principles, universal gravitation cannot be rejected as an obscure phenomenon, which, allegedly unlike the impact among particles, has no objective grounding in the nature of bodies or in the a priori principles of divine action. ${ }^{31}$ Of course, though he is silent about this commitment for the most part in the Siris, the concept of extension was a non-starter for the immaterialist Berkeley, which served as a basis for the Cartesian and even occasionalist advocates of strict mechanism, entailing eternal truths about the impenetrability of bodies, the plenum of the universe and the necessity

they are actual rules God established for us. So, Berkeley is not an instrumentalist about the laws, as the ordering God established has a nomological reality, and the usefulness of a scientific theory depends on how acquainted it makes us with (and how easily it makes us understand) this reality. Certain scientific theories or generalizations are to be regarded as laws God decreed not merely or primarily because they are generally useful to predict the currently unperceived phenomena but, first and foremost, because they provide a proper understanding of God's highly complex system of volitions. Simply put, though usefulness is a sign of truth, the latter cannot be reduced to the former. As Berkeley puts it, the "truer, [is] therefore, the more useful" (Alciphron 5.10). See footnote 20.

31 Even when Newton tries to account for gravity through some mechanical principle, like that of the density of aether, it is criticized by Berkeley. See Siris 225 and 243, cf. the analysis of Airaksinen (2010, 92-94). 
of contact action..$^{32}$ But, for Berkeley, beyond the fact that we experience (and infer from the empirical data) that things attract and repel one another, we need to find no justification whatsoever for attractionism. Strict mechanism, with its intellectualist background assumptions, holds that our experience of attraction can be reduced to more basic terms, allegedly more comprehensible, more real and more in accordance with the intelligible nature of matter or with the intellectual nature of the divinity who moves things around. For Newtonians and/or voluntarists, on the other hand, the laws of nature do not have to, in fact, cannot, be grounded on our concept of the perfect being or of the nature of body, which, as far as we know, "does not exist necessarily but by divine will, because it is hardly given to us to know the limits of the divine power [...] and hence [Newton is] reluctant to say positively what the nature of bodies is [...]" (Newton 1962, 138.). The inductive scientific methodology advocated by Newton is also less at odds with Berkeley's voluntarist conviction that not everything can be explained by a couple of universal (for instance, "strictly" mechanical) laws because God acts arbitrarily and specifically in nature.

\section{Divine Psychology and Simplicity}

So far, we have covered points (ii) to (iv). But does Berkeley's characterization of God support this picture of the laws of nature? The general Platonic atmosphere of the Siris might call it into question, suggesting a more intellectualistic approach to the divine nature. So, in the last section, I turn to the issue of divine psychology in the Siris, and I will argue that Berkeley puts forward, in a Neoplatonic disguise, a voluntarist interpretation of God's nature, basically identifying God's essence with his power to act. As we have seen, God acts in nature freely, arbitrarily and according to his "good pleasure", and, as I will try to establish based on his remarks made in the Siris, God's volitional side enjoys conceptual priority over his intellectual aspect-just as (i) requires from a theological voluntarist.

In the Siris, Berkeley does not give up his early view that, though the volitional activity constitutes the essence of the divine mind (see most clearly in Notebooks 712), its agency is not blind, that is, it always has

32 According to Downing (2005b), Malebranche as an occasionalist cannot consistently avail himself of any a priori consideration against the theory of attractionism. Schmaltz (2008), by contrast, shows that for Malebranche, unlike for Berkeley, a priori reflection on the divine perfections reveals that God acts in the most simple way possible, which determines some of the basic laws of motion, excluding the possibility of action at a distance. 
knowledge or representation of the intentional object it is directed on (see Notebooks 812).

Varro, Tully, and St. Augustine, understand the soul to be vis, the power or force that acts, moves, enlivens. Now although, in our conception, vis, or spirit, might be distinguished from mind, it would not thence follow that it acts blindly or without mind, or that it is not closely connected with intellect. (Siris 322.)

Plotinus indeed saith, that which acts naturally is not intellection, but a certain power of moving matter, which doth not know but only do. And it must be owned that, as faculties are multiplied by philosophers according to their operations, the will may be distinguished from the intellect. But it will not therefore follow that the Will which operates in the course of nature is not conducted and applied by intellect, although it be granted that neither will understands, nor intellect wills. (Siris 254, emphasis added)

As I understand it, being "conducted and applied by intellect" does not entail that the will or the power of the soul that acts is determined in any significant sense by the intellect, or that it is only a secondary function of the divine mind. What Berkeley wants to capture by this phrase is nothing else but what he says in Siris 322 and what he accepted in his earlier writings, namely that the divine mind, just as its human copy, is an intelligent will, which is "closely connected with" and guided by the intellect insofar as its activity is specified by the intentional objects it is directed on..$^{33}$ The mind has to represent the object it wills, but it does not mean that the knowledge of the represented object somehow determines or even limits the possibilities the mind can actually will. ${ }^{34}$ Expressing with regard to the Trinitarian account of God, Berkeley claims that there is no action and power (or authority) without knowledge. These functions of God always and, perhaps, necessarily coexist and cooperate in such an intimate way that they "constitute one Sovereign".

Certain it is that the notion of a Trinity is to be found in the writings of many old heathen philosophers-that is to say, a notion of three divine Hypostases. Authority, Light, and Life did, to the eye of reason, plainly appear to support, pervade, and animate the mundane system or macrocosm. The same appeared in the microcosm, preserving soul and body,

${ }^{33}$ For interpretations of the doctrine of blind agency, see Winkler 1989, 207-216 and Stoneham 2018, 50-53.

${ }^{34}$ Indeed, on my interpretation, the denial of blind agency does not require God to have any ideational representation present in his mind. The doctrine is perfectly satisfied by holding that the divine mind has an intentional object only once it forms a volition, not the other way round: having ideas in his intellect waiting for the will to pick, and actualize, them. 
enlightening the mind, and moving the affections. And these were conceived to be necessary universal principles, co existing and co operating in such sort as never to exist asunder, but on the contrary to constitute one Sovereign of all things. And, indeed, how could power or authority avail or subsist without knowledge? Or either without life and action? (Siris 361.)

Despite the undeniable fact, mentioned in Siris 254, that philosophers (sometimes including Berkeley himself) tend to multiply the mental faculties, Berkeley seems to endorse a form of the divine simplicity thesis along the lines suggested by this passage. The traditional doctrine that God is absolutely simple, and without any sort of composition is often invoked for voluntarist purposes, as we see with Descartes and Arnauld, because it entails that the divine faculties, being identical with God himself, cannot be separated from one another, excluding the possibility of the will being determined by the intellect. ${ }^{35}$ But Berkeley's interpretation of this doctrine is voluntarist in a more positive sense. While restricting the strict sense of simplicity to the first principle of the Trinity (see Siris 342) and identifying a looser sense of simplicity with the close and necessary co-operation of the persons he underlines the conceptual priority of the will. In order to show this, the following crucial, though pretty long, passage is worth quoting in full.

The simplicity of to hen (the Father in the Pythagoric and Platonic Trinity) is conceived such as to exclude intellect or mind, to which it is supposed prior; and that hath created a suspicion of atheism in this opinion: for, saith the learned Doctor Cudworth, shall we say that the first Hypostasis or Person is anous and alogos, senseless and irrational, and altogether devoid of mind and understanding? Or would not this be to introduce a kind of mysterious atheism? To which it may be answered that whoever acknowledgeth the universe to be made and governed by an eternal mind cannot be justly deemed an atheist (Sects. 154, 276, 279, 287). And this was the tenet of those ancient philosophers. In the Platonic doctrine, the generation of the nous or logos was not contingent but necessary, not temporary but from everlasting. There never was a time supposed wherein to hen subsisted without intellect; the priority having been understood only as a priority of order or conception, but not a priority of age. Therefore, the maintaining a distinction of priority between to hen and nous doth not infer that the one ever existed without the other. It follows, therefore,

${ }^{35}$ In fact, the doctrine might cut both ways, as Leibniz's criticism of Spinoza's radical denial of the distinction shows. As Leibniz argues in section 173 of the Theodicy, the failure to distinguish between God's intellect and will (even in modal terms) led Spinoza to remove all freedom and contingency from God's decisions. To be sure, for Leibniz, as an intellectualist, this freedom is compatible with hypothetical and metaphysical or, as he calls it, moral necessity. See, for instance, his fifth letter to Clarke (Leibniz 1989, 696). 
that the Father or to hen may, in a certain sense, be said to be anous without atheism, or without destroying the notion of a Deity; any more than it would destroy the notion of a human soul, if we should conceive a distinction between self and intellect, or intellect and life. To which we may farther add, that it is a doctrine of Platonics, and agrees with their master's tenets, to say that to hen or the first Hypostasis contains all excellence and perfection, whereof it is the original source, and is eminenter, as the Schools speak, intellect and life, as well as goodness; while the second Hypostasis is essentially intellect, and, by participation, goodness and life; and the third, life essentially, and, by participation, goodness and intellect. (Siris 352.)

Even according to the earlier formulations of the denial of blind agency thesis, it is reasonable to regard the agency or the will as the subject which possesses or rather encompasses the knowledge. There is an order of priority with regard to the human mind's functions, as he suggests in this passage as well, claiming that the essence of the soul-referred to as the self, identified earlier with vis or active force or power-is not the intellect, even though, as long as it exists, it is never without it. The mind is a thinking being (cf. Principles 98.), but thinking does not constitute its essence, the volitional agency or activity that describes and distinguishes the mind from the other kind of, in fact less substantial, beings, namely the physical objects constituted by passive perceptions. What he calls self here, referring to agency or the active power of the mind, i.e. the will, has a conceptual priority over its other aspects or functions: if it exists, it always thinks, but the pronoun "it" singles out the purely active agency as the subject of those secondary and tertiary predicates.

Similarly, God's authority or power to act is said to be conceptually prior to intellection. In this striking passage, Berkeley defends the Neoplatonic model of God against the criticism of intellectualists like Cudworth. In contrast to the Cambridge Platonists, Berkeley accepts as proper theism the radically voluntarist view that God is "devoid of [...] understanding" as long as it "acknowledgeth the universe to be made and governed by an eternal mind". Indeed, Berkeley suggests in the Siris that the Neoplatonic hierarchical model, when understood correctly, provides the best characterization of God's nature. What is particularly interesting about this divine psychology is that it combines the denial of blind agency, and along those lines a version of the thesis of divine simplicity, with the conceptual priority of the activity conventionally attributed to the divine will. Berkeley basically claims that the absolutely simple first principle of God is not intrinsically intellectual, and even though, in temporal terms, they do not come apart in his simple nature, the active side of the divinity that we ordinarily refer to as 'will' enjoys "a priority of order or conception" over what we call his 'intellect'. And even if, as the denial of blind agency suggests, Berkeley wanted to 
establish an interdependence relation between the divine will and the intellect that is deeper than a merely temporal one, he could still maintain the priority of the former. For instance, though the relation between a father and a son is interdependent in some sense-one cannot be a father without a son and vice versa-it is not symmetrical, and the father can be said to be prior, for instance causally or existentially, to the son. Indeed, as Berkeley makes clear in Siris 361-2, the Father of the Trinity, rather than the son, who has the authority or power to act. The first principle of God, also called the One in Siris 352, is essentially the maker and governor of the world, who, as he puts it in Siris 254, is what "acts naturally", "a certain power of moving matter" or the divine "Will which operates in the course of nature". This active, volitional aspect of God is said to be his essence, which contains in a higher, potential form, and is hence conceptually prior to, his intellect as well as his goodness, even if it always and necessarily knowledgeable and good. As he reinforces in Siris 362, this "authority to establish", the active principle and the "source of all perfections", precedes the divine intellect (also called reason, order, etc.) "in respect of origin and order", though not of time. One way to spell out this priority is to say that God has knowledge only insofar as he has intentions or volitions to create the represented thing. As one might put it, God has no abstract, purely intellectual knowledge and knows for the sake of creating and not merely for the sake of knowing. For instance, God does not actually entertain mere possibilities in his intellect, and has representations only of what he wills to, and does, bring about. A less radical way to understand the priority might simply be that the will constitutes the defining aspect of God, which, though necessarily directed on some intentional object, is not determined by any of the representations the intellect provides it with. The texts do not help much in determining the exact details, but the point I wanted to emphasize is merely that, in the Siris, through re-interpreting the doctrine of divine simplicity Berkeley subscribes to a Neoplatonic model of the divinity in a characteristically voluntarist manner, instead of endorsing some proto-intellectualistic Platonic models, for instance the concept of a demiurgic God, who merely actualizes or, indeed, copies the eternal ideas his intellect entertains.

\section{Concluding Remarks}

In this paper, I hope to have shown that Berkeley was a theological voluntarist in the Siris. Despite its Platonic tendencies, he endorses all four theses I associated with a full-blown voluntarist position. Most importantly, the arbitrariness and contingency of the laws imply the denial not only of essentialism but also of intellectualism, the view that the laws 
of nature could be determined extrinsically, albeit just as necessarily, by divine ideas, eternal truths or other intellectual principles the divine will is obliged to implement in nature. In accordance with this metaphysical picture, he continued to advocate the inductive method of discovering the nomological order God freely and, in some cases, through highly specific correspondences, established in the natural world. I also proposed that Berkeley's voluntarism might be a reason for his preference for Newtonian attractionism to Cartesian strict mechanism, since it is more in line with denying any allegedly more comprehensible essential attribute, eternal truth or general principle the observed motions should reflect. I tried to show that the divine psychology put forward in the Siris is not only compatible with voluntarism but, after the Neoplatonic reformulation of the doctrine of the divine simplicity, strongly supports it. Moreover, we might be able to draw a more far-reaching conclusion, once we take into account that most of the Siris's argumentation, just like that of the New Theory of Vision, the De Motu or the Alciphron, does not require the truth of immaterialism. ${ }^{36}$ Provided that my interpretation proposed here is correct, the fact that Berkeley nonetheless adopts a theological voluntarist position with respect to many crucial issues shows that voluntarism is an important aspect of his thought logically independent of his famous denial of matter. Indeed, even his denial of material causation, which is a constant theme also in the Siris, is insufficient to establish the strong voluntarism I attribute to him. On my interpretation, Berkeley went significantly further by claiming that even God's intellectual nature does not determine his volitions and actions in the sense Malebranche, for instance, thought so. These considerations suggest that Berkeley's voluntarism is not, as it was claimed by Ayers (2005), an uninteresting and unavoidable consequence of his immaterialism.

\section{Bibliography}

Airaksinen Timo. 2010. "Berkeley and Newton on Gravity in Siris". In: George Berkeley: Religion and Science in the Age of Enlightenment, ed. Silvia Parigi. 87-106. Dordrecht: Springer.

Ayer Michael. 2005. "Was a Berkeley an Empiricist or a Rationalist?". In: The Cambridge Companion to Berkeley, ed. Kenneth Winkler. 34-62. Cambridge: Cambridge University Press.

Astell Mary. 1705. The Christian Religion, as profes'd by a Daughter of the Church of England. London: S. H. for R. Wilkin.

36 This is, of course, not to suggest their incompatibility. See, for instance, Siris 251 and 292 (quoted above), where Berkeley comes close to betraying his immaterialism by identifying the natural phenomena with appearances in the mind. 
Berkeley George. 1948-1957. The Works of George Berkeley. 9 vols., eds. A. A Luce and T. E. Jessop. London: Thomas Nelson. (Referred to as Works, reference is by volume and page number).

Brook Richard. 1973. Berkeley's philosophy of science. The Hague: M. Nijhoff.

Buchdahl Gerd. 1969. Metaphysics and the philosophy of science: the classical origins Descartes to Kant. Oxford: Basil Blackwell.

Downing Lisa. 1995. "Siris and the Scope of Berkeley's Instrumentalism," The British Journal for the History of Philosophy 3 (2): 279-300.

Downing Lisa. 2005a. "Berkeley's Natural Philosophy and Philosophy of Science". In: The Cambridge Companion to Berkeley, ed. Kenneth Winkler. 230-265. Cambridge: Cambridge University Press.

Downing Lisa. 2005b. "Occasionalism and Strict Mechanism: Malebranche, Berkeley, Fontenelle". In: Early Modern Philosophy: Mind, Matter, and Metaphysics, eds. Christia Mercer and Eileen O'Neill. 206-230. Oxford: Oxford University Press.

Garber Daniel. 1982. "Locke, Berkeley, and Corpuscular Scepticism”. In: Berkeley: Critical and Interpretative Essays, ed. C. M. Turbayne, 174-193. Minneapolis: University of Minnesota Press.

Hight Marc A. 2010. “Berkeley's Metaphysical Instrumentalism”. In: George Berkeley: Religion and Science in the Age of Enlightenment, ed. Silvia Parigi. 15-29. Dordrecht: Springer.

Leibniz Gottfried Wilhelm. 1989. Philosophical Papers and Letters. A Selection: A Selection Translated and Edited, with an Introduction by Leroy E. Loemker. 2nd edition. Dordrecht: Kluwer Academic Publishers.

Leibniz Gottfried Wilhelm. 1952. Theodicy, trans. E. M. Huggard. New Haven: Yale University Press.

Locke John. 1975. An Essay Concerning Human Understanding, ed. Peter H. Nidditch, Oxford: Clarendon Press. (Reference is by book, chapter and section).

Moked Gabriel. 1971. "A note on Berkeley's corpuscularian theories in Siris". Studies in History and Philosophy of Science 2 (3): 257-266.

Moked Gabriel. 1986. “Two Central Issues in Bishop Berkeley's 'Corpuscularian Philosophy' in the Siris". History of European Ideas 7 (6) 633-641.

Moked Gabriel. 1988. Particles and Ideas: Bishop Berkeley's Corpuscularian Philosophy. Oxford: Clarendon.

Newton Isaac. 1962. Unpublished Scientific Papers of Isaac Newton, eds. A. Rupert Hall and Marie Boas Hall. Cambridge: Cambridge University Press.

Newton Isaac. 1999. The Principia. Mathematical Principles of Natural Philosophy. A New Translation by I. Bernard Cohen and Anne Whitman assisted by Julia Budenz. Berkeley, Los Angeles, London: University of California Press.

Ott Walter. 2019. “Berkeley's Best System: An Alternative Approach to Laws of Nature". Journal of Modern Philosophy 1 (1), 4: 1-13.

Pearce Kenneth. 2017. Language and the Structure of Berkeley's World. Oxford: Oxford University Press. 
Peterschmitt Luc. 2009. “Can Berkeley Be an Instrumentalist? Towards a Reappraisal of Berkeley's Philosophy of Science". Berkeley Studies 19: 19-31.

Schmaltz Tad M. 2008. “Occasionalism and mechanism: Fontenelle's objections to Malebranche". British Journal for the History of Philosophy 16 (2): 293-313.

Stoneham Tom, Angelo Cei. 2009. "Let the Occult Quality Go: Interpreting Berkeley's Metaphysics of Science". European Journal of Analytic Philosophy 5 (1): 73-91.

Stoneham Tom. 2018. "Action, knowledge and embodiment in Berkeley and Locke". Philosophical Explorations 21 (1): 41-59.

Wilson Catherine. 1994. "Berkeley and the Microworld". Archiv für Geschichte der Philosophie 76 (1): 37-64.

Winkler Kenneth. 1989. Berkeley: An Interpretation. Oxford: University Press.

\section{Summary}

In this paper, I argue that Berkeley was a theological voluntarist in the Siris. I define theological voluntarism as the view that the divine will has conceptual priority over the intellect, implying serious ramifications for the modal status of the laws of nature. I identify four theses that are required to call Berkeley a full-blown voluntarist and show that we find all of them in the Siris: (i) God's indifferent, arbitrary and free will enjoys conceptual priority over his intellectual functions; (ii) nature is directly guided by, and its laws are grounded in, God's will, meaning not only that physical things have no causal powers or essences which could ground the laws of nature; but also that (iii) God creates and maintains the physical world in accordance with law-like patterns of the phenomena arbitrarily established by particular divine volitions. As a consequence, (iv) whatever we can know about the metaphysically contingent laws of nature we know through induction from our limited experience. The Siris is particularly interesting from the perspective of voluntarism underlying these views, as, due to the alleged discontinuities with the early works and its Platonic tendencies in general, it seems to be the worst candidate for such an interpretation. In what follows, my principal aim is to show how wrong this appearance is, and that the voluntarist views Berkeley put forward in the Siris concerning the divine nature, the God-world relation, the laws of nature and the proper scientific methodology link it very naturally to his earlier considerations.

Keywords: Berkeley, Siris, laws of nature, voluntarism, divine psychology

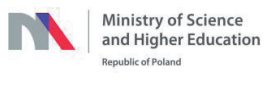

Financed by MNiSW on the basis of agreement no. 655/P-DUN/2019 (dated May, 7, 2019). Project 2: "Publishing four issues of 'Ruch Filozoficzny' quarterly in English over the period 2019-2020; vol. LXXV - issues 2 and 4 (2019); vol. LXXVI - issues 2 and 4 (2020)"; amount from the DUN grant: 35200 PLN. 